\title{
Prevalence of low vision among adults in Galle District, Sri Lanka
}

\author{
Ubeysekara HA ${ }^{1}$, Wijayaratne WMDGB ${ }^{2}$, Fonseka $P^{3}$, Wimalasundara $\mathrm{S}^{2}$ \\ ${ }^{\text {I}}$ Provincial Director of Health Services Office, Southern Province, Sri Lanka. \\ ${ }^{2}$ Faculty of Medicine, University of Ruhuna, Galle, Sri Lanka. \\ ${ }^{3}$ Faculty of Medical Sciences, University of Sri Jayawardenapura, Sri Lanka.
}

Correspondence: Dr.H A Ubeysekara

e-mail: hubeysekara@yahoo.co.uk

(1) https://orcid.org/0000-0002-1917-6845

\begin{abstract}
Introduction: The global initiative to prevent avoidable blindness in the world has taken several measures to accomplish their theme "Vision 2020 - Right to Sight". However, visual problems still remain among the least priority in preventive care. Visual impairment is common after 40 years of age. Thus, it is important to identify the problem of low vision in the community where majority can be easily identified and corrected with minimum cost. This study was aimed to determine the prevalence of low vision among adults aged 40 - 60 years in Galle District, Sri Lanka.
\end{abstract}

Methods: A Community based cross sectional study conducted in Galle District among adults aged 40 - 60 years. Multistage cluster-sampling method was adapted to select subjects from both urban and rural areas in the district. An interviewer administered questionnaire was administered to collect their demographic and social information followed by checking the visual acuity (VA), using the Snellen chart in the standard manner.

Results: A sample of 708 people recruited and the majority $(30.8 \%, \mathrm{n}=218)$ were in the $40-44$ years age group with a mean age of 49.0 (SD 6.2) years. There were $52.3 \%(n=370)$ females in the study sample with a male, female ratio of $1: 1.09$. Of the study sample, $88.9 \%(n=630)$ were from the rural sector. The prevalence of low vision and blindness for the uncorrected VA was 37.1\% $(n=263)(C I 95 \% 33.5-40.7)$ and $0.6 \%(n=4)(C I 95 \%$ $0.56-0.65)$ respectively. Thus the total with visual impairment in the study sample was $37.7 \%(\mathrm{n}=267)$. When considering the presenting VA, the prevalence of low vision and blindness was $28.1 \%$ (n=199) (95\% CI: 24.8 $31.4)$ and $0.4 \%(n=03)(95 \%$ CI: $0.37-0.43)$ respectively. The total visual impairment of the study sample was $28.5 \%(n=202)$. Among all people with visual impairment, $24.3 \%(65 / 267)$ have already corrected their defects.

Conclusions and Recommendations: The prevalence of uncorrected low vision among adults aged 40 - 60 years in Galle district was approximately thirty seven percent. Majority of people with visual impairment have not corrected their defects. Therefore, the policy makers and the health planners have to look into this problem to address the correctable proportion with low vision in this population.

Keywords: Adults, low vision, Sri Lanka

\section{Introduction}

"Vision 2020 - Right to sight" is the theme of global initiative to prevent avoidable blindness in the world. Sight is a gift given by nature to everybody healthy when they are born but can lose it due to many reasons. According to previous studies, many causes of blindness are avoidable or correctable by recognizing the problem at the correct time and providing simple interventions and modifying relevant risk factors.

The first global estimation of visual impairment done in 1975 indicates that 28 million people were 
blind. The estimates done in 1996 reveal that there were 45 million people who were blind and another 135 million with low vision. Among those who were blind, $60 \%$ were due to refractive errors and cataract. When these data are projected to the 2020 world population, it has been estimated that this will be doubled in 2020. Out of all treatable eye diseases and treatable causes of blindness, it has been estimated that $75 \%$ of all blindness in the world could have been prevented

Sri Lanka is lacking data regarding the magnitude of visual problems in the community except for a few individual studies conducted on this. The census population and housing survey conducted by the Department of Census and Statistics, Sri Lanka have looked into disabilities in seeing as self-reported by participants. It reports that 41.0 per 10,000 population in Sri Lanka have some sort of disability either due to total blindness, blindness in one eye or due to weak vision. Out of the total male population, 46.6 per 10,000 and out of the total female population 48.7 per 10,000 are having difficulty in seeing. Galle District Department of Census and Statistics reports that 47.7 per 10,000 population in Galle district have difficulty in seeing. The prevalence of blindness in Sri Lanka was nearly $0.5 \%$ according to the survey conducted by Eye Care Sri Lanka in 20 districts. They have found that $66 \%$ of total blindness was due to cataract .

First national Steering Committee for the Prevention and Control of Blindness in Sri Lanka was established in year 2001 following the launching of "Vision 2020 - Right to Sight" global programme. The national eye care plan was laid down in 2004 in line with vision 2020 priorities .

In Sri Lanka the data on low vision has not being reported and therefore not published in the Annual Health Bulletin. Some patients with these problems are managed at out-patient clinics and at private sector. These data are usually not recorded. It is important to identify the problem of low vision in the community, out of which refractive errors that can be corrected easily and cheaply. Knowing the magnitude of the problem will support the health planners and managers to launch their activities at grass root level to address the needy people in the community in order to achieve the goals of vision 2020. Therefore, this study was designed to determine the prevalence of low vision among adults aged 40 - 60 years in the Galle district.

\section{Methods}

A community based cross sectional study was conducted in Galle District of Southern Province, Sri Lanka to determine the prevalence of low vision among adults aged 40 - 60 years in 2011. Galle District has a population of 990,487 belonging to a mixed ethnicity in a land area of $1617 \mathrm{~km}^{2}$. Majority $(87 \%)$, of the population reside in rural areas with urban to rural ratio of $1: 8$. Thirty four percent of population belongs to the age category of $40-60$ years .

The sample size was calculated using formula [n $\left.=\mathrm{Z}_{1-\alpha / 2}^{2} P(1-P) / \mathrm{d}^{2}\right]$ for the descriptive study. According to previous studies done in the Galle district, the prevalence of low vision was $28.8 \%$. Therefore, a prevalence of $30 \%$ was used as the anticipated population proportion of low vision in this study. Z score of 1.96 corresponding to an alpha error of $5 \%$, P value of 0.3 and absolute precision (d) of 0.05 considered.

Since cluster-sampling method was adapted the calculated sample size $(n=323)$ was multiplied by the design effect to overcome effects of clustering. This is usually estimated using the results of previous studies of similar design and subjects. Due to the unavailability of previous information about the degree of homogeneity the design effect was taken as two. Further, to compensate for dropout rate another $10 \%$ was added to the sample. Accordingly, the total sample size was 711 . Since data was collected from 36 equal clusters (20 study subjects from each cluster) the recapitulated final sample size was 720 .

Adults between 40 - 60 years who have been residing in the Galle district for a continuous period of three months or more from the date of data collection were included into the study from the selected households. If a single house had more than one family, all families were included into the study and all eligible individuals in a single household were included. Any person who was found to be bed bound among those who fulfilled criteria given under the inclusion criteria was excluded as it was difficult to measure the visual acuity (VA) in them. 
To ensure the proportional representation of the urban and rural subjects in the sample, selection of 36 clusters was done at the level of Grama Niladari (GN) divisions located in both areas proportionate to the urban / rural population proportion in the Galle district. In the field, the starting point for recruitment of eligible subjects from a cluster was done by going to the office of the GN in the particular cluster and selecting the direction randomly. All households on either side of the road in that direction was screened for eligible individuals until the required sample size of 20 people were selected.

The principal investigator and six pre-intern medical officers as data collectors and the area GN comprised the field team. The data collectors were trained at the Community Ophthalmology Centre, Faculty of Medicine, University of Ruhuna by a Community Ophthalmologist to refresh their knowledge onVA checking, basic eye examination and on identification of cataract using torch light. Community Ophthalmologist rechecked fifty percent of the study subjects in the field to assess the reliability of field examination and diagnosis. Difficult cases were referred to the Community Ophthalmology Centre for specialist opinion and people with cataract were referred to the Teaching Hospital Karapitiya for necessary treatment.
After obtaining the informed consent an interviewer administered questionnaire was administered. Then the visual acuity was measured using the Snellen chart in the standard manner. Presenting VA was assessed using a standard Snellen chart of numbers (non-illuminating type) at 6 meters. For those who are illiterate tumbling E type of Snellen chart was used. Whenever possible the VA was assessed in good light, outdoors in a seated position. Each eye was tested while the opposite eye was covered. Person was asked to read from top line first and then the next line below. Once a person has started a line, he or she should finish by guessing at all 5 letters on that line. Once at least three letters are missed on a line and all letters on that line have been attempted, then the person has completed that VA measure.

The study participants were grouped into four categories namely normal vision, mild visual defect, low vision and blind, according to their VA level in the better eye (Figure 1), and the VA was measured with and without correction. Following definitions used by World Health Organization were used in this study.

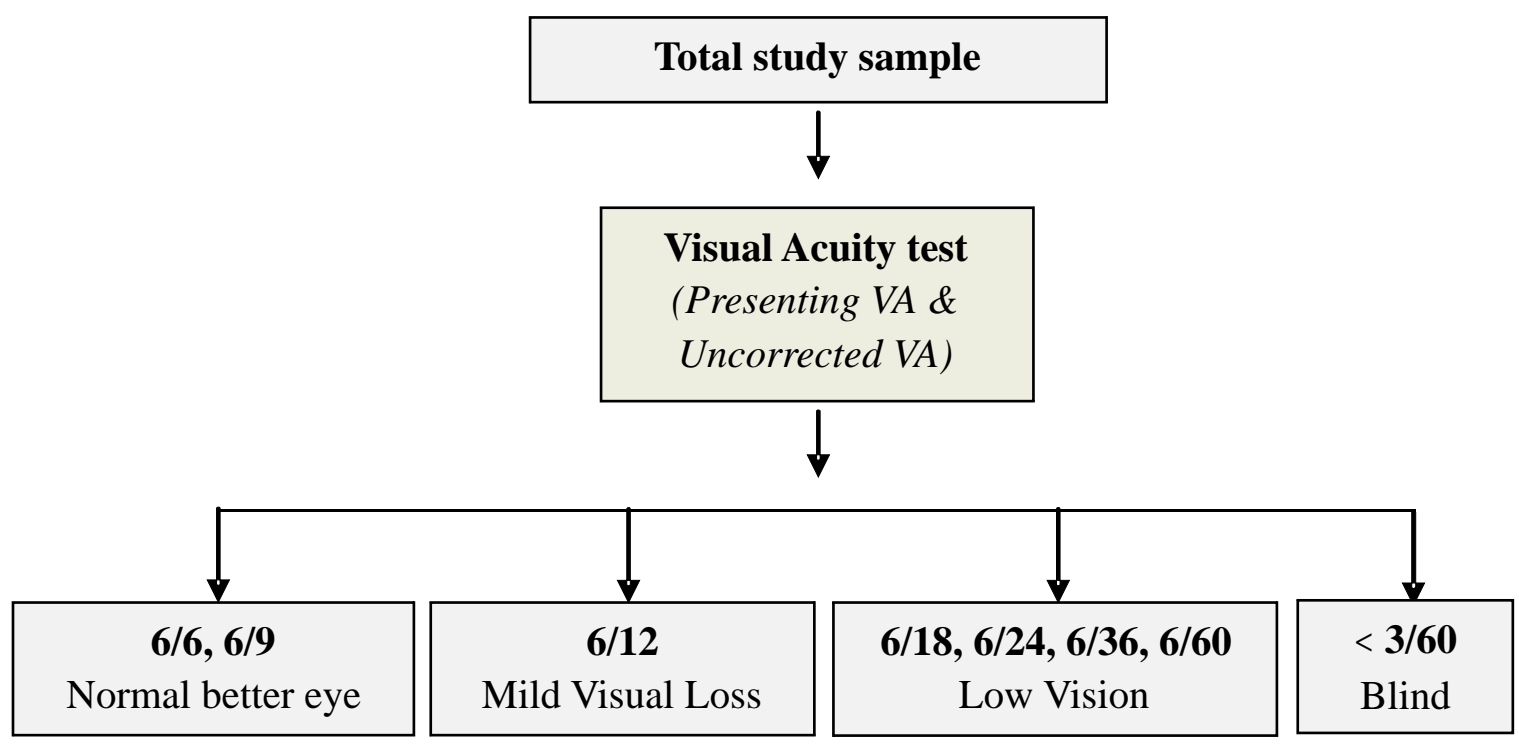

Figure 1: An outline of analysis of the study 


\section{Normal vision}

Normal vision has been defined as VA of more than $6 / 9$ in better eye (i.e. $6 / 6$ or $6 / 9$ in the better eye).

\section{Low vision}

Low vision has been defined as VA less than $6 / 18$ and equal to or better than $3 / 60$ in the better eye.

\section{Visual impairment}

Visual impairment has been defined as VA of less than $6 / 18$ in the better eye spanning the low vision and blindness categories as defined above.

\section{Mild visual impairment}

The VA 6/12 in better eye was defined as mild visual impairment.

\section{Blindness}

Blindness has been defined as VA of less than 3/60 in the better eye or inability to count fingers at a distance of 3 meters in the better eye with or without available means of correction (with spectacles when available).

\section{Uncorrected VA}

VA measured without correction (presenting VA on those who are not wearing spectacles and VA without spectacles in those who were wearing spectacles or contactlenses).

\section{Presenting VA}

VA measured with spectacles in those who are wearing spectacles or contact lenses (may not be the best corrected VA) and VA without spectacles in those who are not wearing spectacles or contact lenses.

Statistical analysis was done using Epi Info (TM) 3.4.3 database and statistics software for public health professionals from the Centers for Disease Control and Prevention and the SPSS 15.0 software.

Ethical approval was obtained from the Ethics Review Committee, Faculty of Medicine, Galle.
Permission was obtained from the relevant administrative and health authorities. Informed consent obtained from all participants and were given the option to withdraw from the study at any time. The obtained data was handled as grouped data preserving the confidentiality.

\section{Results}

The study sample enrolled was 708 persons aged 40 - 60 years, which is within the sample size calculated with non-responders. All subjects gave their consent to participate in the study and the non-response rate was nil.

The distribution of basic demographic characteri-stics of the respondents is presented in Table 1. When comparing the study sample with Galle District census and population statistics, a significant deference in the distribution were found between age groups $(p<0.01)$ and ethnicity $(p<0.01)$ of the study sample and Galle District population. This may be due to extraction of district statistics from 2001 demographic survey on population and housing, after which age group of cohorts may have been shifted. Also, the difference in ethnicity may be due to clustering of religious and other ethnic groups in the normal geographical distribution.

Of the 708 individuals who participated, 338 were males. Majority belonged to the age group of 40 - 44 years and $88.4 \% \quad(n=626)$ of the sample were married.

Among study participants $40.4 \% \quad(n=286)$ had a monthly household income between $>$ Rs. 5,000 to 10,000 rupees while $12.7 \%(\mathrm{n}=90)$ had a monthly income > Rs. 20,000. Mean monthly income was Rs. 13,516.95 (SD 8729.33) while the range was $2,500-75,000$ rupees.

The social class of study subjects was calculated according to the social class categorization given by Barker and Hall. According to this 33.3\% $(n=236)$ were in Social Class III, 25.9\% $(\mathrm{n}=183)$ in Social Class V, 22.7\% $(\mathrm{n}=161)$ in Social Class IV and approximately $17.0 \%(\mathrm{n}=123)$ in Social Class II. Among males $71.4 \%(\mathrm{n}=241)$ and among females $64.0 \%(n=237)$ had an education level equal to or greater than General Certificate ExaminationOrdinary Level [GCE (O/L)]. 
Table 1: Distribution of demographic and socio-economic characteristics

\begin{tabular}{|c|c|c|c|c|}
\hline \multirow{2}{*}{ Characteristics } & \multicolumn{2}{|c|}{ Study } & \multicolumn{2}{|c|}{$\begin{array}{l}\text { Adult Group Population } \\
\text { in the District }\end{array}$} \\
\hline & No. & $\%$ & No. & $\%$ \\
\hline \multicolumn{5}{|l|}{ Age in years } \\
\hline $40-44$ & 218 & 30.8 & 64,868 & 29.8 \\
\hline $45-49$ & 163 & 23.0 & 57,076 & 26.2 \\
\hline $50-54$ & 152 & 21.5 & 53,033 & 24.4 \\
\hline$\geq 55$ & 175 & 24.7 & 42,725 & 19.6 \\
\hline Total & 708 & 100.0 & 217,702 & 100.0 \\
\hline \multicolumn{5}{|c|}{ Mean age \pm SD $=49.0 \pm 6.2$ years, Median $=48$ in years, Min $/$ Max $=40 / 60$ years } \\
\hline \multicolumn{5}{|c|}{ Sex } \\
\hline Male & 338 & 47.7 & 103,094 & 47.4 \\
\hline Female & 370 & 52.3 & 114,608 & 52.6 \\
\hline Total & 708 & 100.0 & 217,702 & 100.0 \\
\hline \multicolumn{5}{|c|}{ Area of residence/ Sector } \\
\hline Urban & 78 & 11.1 & 25,130 & 11.7 \\
\hline Rural & 630 & 88.9 & 188,504 & 88.2 \\
\hline Total & 708 & 100.0 & $213,634^{* * *}$ & 100.0 \\
\hline \multicolumn{5}{|l|}{ Ethnicity } \\
\hline Sinhalese & 689 & 97.3 & 206,991 & 95.2 \\
\hline Tamil & 3 & 0.4 & 3,942 & 1.8 \\
\hline Moor and other & 16 & 2.3 & 6,571 & 3.0 \\
\hline Total & 708 & 100.0 & 217,504 & 100.0 \\
\hline \multicolumn{5}{|l|}{ Religion } \\
\hline Buddhist & 686 & 96.9 & 206,240 & 94.8 \\
\hline Hindu & 3 & 0.4 & 2,954 & 1.4 \\
\hline Islam & 16 & 2.3 & 6,697 & 3.0 \\
\hline $\begin{array}{l}\text { Roman Catholic/ } \\
\text { Christian \& other }\end{array}$ & 3 & 0.4 & 1,811 & 0.8 \\
\hline Total & 708 & 100.0 & 217,702 & 100.0 \\
\hline
\end{tabular}

\section{Visual acuity in the study sample}

Out of the total study sample of 708 people, $12.1 \%$ $(\mathrm{n}=86)$ were using spectacles or contact lenses at the time of enrollment.

The distribution of uncorrected VA and the presenting VA of the study subjects are shown in tables 2 and 3 respectively. The prevalence of low vision and blindness of the above two groups are shown in the table 4 . The prevalence of low vision in the uncorrected and presenting subjects was $37.1 \%$ and $28.1 \%$ respectively. The percentage of subjects with visual impairment was $28.5 \%(202 / 708)$ at the presentation and $37.7 \%(267 / 708)$ when uncorrected indicating that only $24.3 \%(65 / 267)$ people with visual impairment had already corrected their defects at the time of the study. 
Table 2: Distribution of uncorrected visual acuity

\begin{tabular}{lrrrrrrrr}
\hline \multirow{2}{*}{$\begin{array}{l}\text { Uncorrected } \\
\text { Visual acuity }\end{array}$} & \multicolumn{2}{c}{ Right eye } & \multicolumn{2}{c}{ Left eye } & \multicolumn{2}{c}{ Both eyes } & \multicolumn{2}{c}{ Better eye } \\
\cline { 2 - 9 } & No. & \% & No. & \% & No. & \% & No. & \% \\
\hline $6 / 6,6 / 9$ & 355 & 50.1 & 363 & 51.3 & 333 & 68.9 & 384 & 55.6 \\
$6 / 12$ & 49 & 6.9 & 44 & 6.2 & 19 & 3.9 & 57 & 8.6 \\
$6 / 18$ & 73 & 10.3 & 81 & 11.4 & 32 & 6.6 & 85 & 10.6 \\
$6 / 24$ & 90 & 12.7 & 92 & 13.0 & 39 & 8.1 & 88 & 11.9 \\
$6 / 36$ & 64 & 9.0 & 55 & 7.8 & 17 & 3.5 & 45 & 6.4 \\
$6 / 60$ & 67 & 9.5 & 63 & 8.9 & 39 & 8.1 & 45 & 6.4 \\
$\leq 3 / 60$ & 10 & 1.4 & 10 & 1.4 & 4 & 0.8 & 4 & 0.6 \\
\hline Total & $\mathbf{7 0 8}$ & $\mathbf{1 0 0 . 0}$ & $\mathbf{7 0 8}$ & $\mathbf{1 0 0 . 0}$ & $\mathbf{4 8 3}^{*}$ & $\mathbf{1 0 0 . 0}$ & $\mathbf{7 0 8}$ & $\mathbf{1 0 0 . 0}$ \\
\hline
\end{tabular}

"Subjects with different VA in both eyes (225) were not included.

${ }^{*}$ Percentages may not sum to $100 \%$ due to rounding error.

Table 3: Distribution of presenting (corrected) visual acuity

\begin{tabular}{lrrrrrrrr}
\hline \multirow{2}{*}{$\begin{array}{l}\text { Presenting } \\
\text { Visual acuity }\end{array}$} & \multicolumn{2}{l}{ Right eye } & \multicolumn{2}{l}{ Left eye } & \multicolumn{2}{l}{ Both eyes } & \multicolumn{2}{l}{ Better eye } \\
\cline { 2 - 8 } & No. & $\%$ & No. & $\%$ & No. & $\%$ & No. & $\%$ \\
\hline $6 / 6,6 / 9$ & 415 & 58.6 & 415 & 58.6 & 386 & 74.5 & 443 & 62.6 \\
$6 / 12$ & 49 & 6.9 & 56 & 7.9 & 24 & 4.6 & 63 & 8.9 \\
$6 / 18$ & 69 & 9.7 & 71 & 10.0 & 29 & 5.6 & 70 & 9.9 \\
$6 / 24$ & 76 & 10.7 & 73 & 10.3 & 37 & 7.1 & 66 & 9.3 \\
$6 / 36$ & 44 & 6.2 & 36 & 5.1 & 11 & 2.1 & 29 & 4.1 \\
$6 / 60$ & 46 & 6.5 & 48 & 6.8 & 28 & 5.4 & 34 & 4.8 \\
$\leq 3 / 60$ & 9 & 1.3 & 9 & 1.3 & 3 & 0.6 & 3 & 0.4 \\
\hline Total & $\mathbf{7 0 8}$ & $\mathbf{1 0 0 . 0}$ & $\mathbf{7 0 8}$ & $\mathbf{1 0 0 . 0}$ & $\mathbf{5 1 8}$ & $\mathbf{1 0 0 . 0}^{* *}$ & $\mathbf{7 0 8}$ & $\mathbf{1 0 0 . 0}$ \\
\hline
\end{tabular}

"Subjects with different VA in both eyes (190) were not included.

** Percentages may not sum to $100 \%$ due to rounding error.

Table 4: Prevalence of categories of vision according to uncorrected VA and presenting VA

\begin{tabular}{lrrcrrr}
\hline & \multicolumn{3}{c}{ Uncorrected Visual Acuity } & \multicolumn{3}{c}{ Presenting Visual Acuity } \\
\cline { 2 - 7 } & No. & \% & CI & No. & \% & CI \\
\hline Mild visual defect & 57 & 8.1 & $7.52-8.71^{*}$ & 63 & 8.9 & $8.3-9.6^{*}$ \\
Low vision & 263 & 37.1 & $33.5-40.7$ & 199 & 28.1 & $24.8-31.4$ \\
Blind & 4 & 0.6 & $0.56-0.65^{*}$ & 3 & 0.4 & $0.37,0.43^{*}$ \\
Normal & 384 & 54.2 & & 443 & 62.6 & \\
\hline Total & $\mathbf{7 0 8}$ & $\mathbf{1 0 0 . 0}$ & & $\mathbf{7 0 8}$ & $\mathbf{1 0 0 . 0}$ & \\
\hline
\end{tabular}

* confidence interval for exact probability test was used 


\section{Discussion}

The magnitude of the problem of low vision has not been studied properly until the vision 2020 global initiative in 1999. The under estimation of actual situation may be due to the different definitions used in interpreting results (12). The best corrected VA in better eye as in the International Statistical Classification of Diseases (ICD) has been used to define visual impairment, low vision and blindness in many of the studies which sparse the actual number with disease (13). Therefore, the real magnitude of the visual impairment should be more than the above in reality.

This study was conducted in the age group of 40 - 60 years because visual impairment is more prevalent in this age group. The effect on occupation, household activities and on the productivity of the country is high in this age group. Other population based studies done in the world have also targeted the age group above 40 years (14). The distribution of age, sex, ethnicity and the place of residence (urban : rural) were closely represented in the study sample and the Galle district target population ensuring the accurate representativeness of the sample.

Visual acuity is the measure of resolving power of the eye, i.e. the ability to distinguish details and the shape of objects. It is the primary measure of visual function in both research and clinical settings. In this study Snellen chart was used to check VA as it is commonly used in community based studies due to wide availability and familiar to data collectors. When classifying persons with visual loss, the definitions and cut offs of VA used by the different researchers were diverse. In this study VA was measured with and without correction and classified according to the Figure 1.

In the study population $55.6 \%$ of people were normal in their better eye without correction. When considering the presenting VA, $62.6 \%$ were normal in their better eye. Only $24.3 \%$ of people in the community with visual impairment have corrected their defects by the means of spectacles or contact lenses by the time of the study. Among the rest majority could improve their vision with an intervention. But some defects could not be totally corrected and they may remain as people with uncorrectable visual impairment.
The prevalence of low vision without correction (by spectacles or contact lenses) was $37.1 \%$ in this study. A previous study done in Sri Lanka in a population above 20 years of age, revealed prevalence of low vision as $16.6 \%$. This difference may be due to age group variation since low vision is more common after 40 years of age (5).

In this study, when considering the presenting VA, the prevalence of low vision was $28.1 \%$. But "The Kandy eye study" done in the central part of Sri Lanka found that the prevalence of uncorrected visual impairment among inhabitants equal to or more than 40 years of age was very low $(5.9 \%)$ (16).

The prevalence of blindness without correction in this study was $0.6 \%$ which is comparable to findings of a previous study in Sri Lanka (0.5\%) (5) and to that reported in Singapore $(0.5 \%)$ (15). In the world population, $0.85 \%$ were blind $(\leq 3 / 60)$ with the best corrected vision (17). The study conducted in Kandy, Sri Lanka found that the prevalence of blindness in population of above 40 years of age was $1.1 \%$ (95\% CI 0.002-0.020) (16), while in the present study it was $0.4 \%$ when considering the presenting VA.

\section{Conclusions}

The prevalence rate of uncorrected low vision among adults aged 40 - 60 years in Galle district was approximately thirty seven percent. Only a quarter of of people in the community with visual impairment have corrected their defects. Among the rest majority could improve their vision with an intervention.

\section{Recommendations}

Similar studies are recommended in other parts of the country to study the magnitude of the problem and to utilize this data in planning and implementation of eye care services in the country. Detection and correction of visual defects should be done at grass root level via low vision clinics conducted at $\mathrm{MOH}$ level. Also people should be motivated to attend services by increasing awareness of gravity of the problem. 


\section{Limitations}

The study was carried out in Galle district, Southern Province of Sri Lanka where the findings may not be generalised to the country. The study was restricted to people who speak and understand Sinhala.

Authors declare no conflicts of interests.

\section{References}

1. World Health Organization. World health Organization. Monitoring committee for the elimination of avoidable blindness, Vision 2020 - The right to sight: the global initiative for the elimination of blindness, Report of the first meeting. Geneva. 2006.

2. Frick KD, Foster A. The Magnitude and Cost of Global Blindness: An Increasing Problem That Can Be Alleviated. Am J Ophthalmol, 2003; 135(4): 471-6.

3. Department of Census and Statistics. Information on disabled persons; Census population and housing - 2001, Sri Lanka. 2001.

4. Department of Census and Statistics. Census population and housing 2001 - Population and Housing Data, Galle District. 2001.

5. Wimalasundara S. Fighting for Sight through Community Eye Care in Southern Sri Lanka. In Oration of fifth academic sessions, University of Ruhuna; 2008.

6 Ministry of Health. National programme for prevention and control of avoidable blindness in Sri Lanka - five-year plan. Ministry of Health, 2007-12. 2007.

7. Lemeshow S, Hosmer Jr DW, Klar J and, Lwanga SK. Adequacy of Sample Size in Health Studies. $1^{\text {st }}$ ed. John Wiley \& Sons England; 1991.

8. Wimalasundara S, Kumari RAC. A preliminary epidemiology survey of eye diseases in adult rural population of Southern Sri Lanka. J Coll Ophthalmol Sri Lanka, 2002; 8: 22-4.
9. World Health Organization. Global Initiative for the Elimination of Avoidable Blindness, 2006 - 2011 action plan. Geneva. 2007.

10. World Health Organization. Consultation on development of standards for characterization of vision loss and visual functioning. Prevention of Blindness and deafness. Geneva. 2003.

11. Barker DJP, Hall AJ. Practical epidemiology. $4^{\text {th }}$ ed. Churchill Livingstone, London; 1991.

12. Dandona L, Dandona R, What is the global burden of visual Impairment. BMCMed, 2006; 4: 4-6.

13. Krishnaiah S, Srinivas M, Khanna RC, Rao GN. Prevalence and risk factors for refractive errors in the South Indian Adult population: Andhra Pradesh Eye Disease Study. Clin Ophthalmol, 2009; 3: 17-27.

14. Gupta A, Casson RJ, Newland HS, Muecke J, Landers J, Selva D, Aung T. Prevalence of refractive error in rural Myanmar: the Meiktila Eye Study. Ophthalmology, 2008; 115(1): 26-32.

15. Saw SM, Foster PJ, Gazzard G. Causes of blindness, low vision, and questionnaire-assessed poor visual function in Singaporean Chinese adults: the Tanjong Pagar Survey. Ophthalmology, 2004; 111: 1161-8.

16. Edussuriya K, Sennanayake S, Senaratne T, Marshall D, Sullivan T, Selva D, Casson RJ. The prevalence and causes of visual impairment in central Sri Lanka the Kandy Eye study. Ophthalmology, 2009; 116(1): 52-6.

17. West S, Sommer A. Prevention of blindness and Priorities for the future. Bull World Health Organ, 2001; 79: 244-8. 